\title{
Reduced northern source water and ventilation during the Last Glacial Maximum in the Indian Ocean sector of the Southern Ocean linked to a "deep gateway" effect
}

\author{
ELISABETH L. SIKES ${ }^{1}$, THOMAS J. WILLIAMS ${ }^{2}$, AIDAN \\ STARR $^{3}$, ELLEN E. MARTIN ${ }^{2}$ \\ ${ }^{1}$ Marine and Coastal Sciences, Rutgers University, New \\ Brunswick, New Jersey, USA sikes@marine.rutgers.edu \\ ${ }^{2}$ Department of Geological Sciences, University of Florida; \\ thomas.williams@ufl.edu and eemartin@ufl.edu \\ ${ }^{3}$ School of Earth and Ocean Sciences Cardiff University, \\ StarrA1@cardiff.ac.uk
}

Shoaling of northern-sourced waters during the Last Glacial Maximum (LGM) likely contributed to the observed reduction of glacial atmospheric $\mathrm{CO}_{2}$. Previously published work comparing vertical transects of $\delta^{13} \mathrm{C}$ and $\delta^{18} \mathrm{O}$ in cores from the South Atlantic and South Pacific identified a "deep gateway" effect whereby the absence of a net zonal circumpolar pressure gradient above the Drake Passage sill depth prevented net meridional geostrophic transport of intermediate depth northern-sourced waters (NSW) into the Southern Ocean. The effects of this gateway effect should be evident in the Indian Ocean, immediately down-stream of the inflow of NSW into the modern Southern Ocean. However, evidence of this has remained elusive in the Indian Ocean due to a lack of strategically-placed cores. We present data from two new cores the Southeast Indian Ocean, TT1811-34GGC $\left(41.718^{\circ} \mathrm{S}\right.$, $80.163^{\circ} \mathrm{W}, 3167 \mathrm{~m}$. water depth) bathed in Circumpolar Deep Water (CDW) and TT1811-50GGC $\left(38.334^{\circ} \mathrm{S}, 77.715^{\circ} \mathrm{W}\right.$, $1118 \mathrm{~m}$.) bathed in Antarctic Intermediate Water (AAIW). Reconstructions of Holocene - LGM $\delta^{13} \mathrm{C}$ differences of $\sim 1 \%$ based on Cibicidoides spp. indicate increased respired $\mathrm{CO}_{2}$ and neodymium isotopes $\left(\varepsilon_{\mathrm{Nd}}\right)$ measured on uncleaned planktic foraminifera (-8.63 in core top; -6.5 in the LGM) in our deep core (34GGC) indicate significantly reduced NSW in the LGM. Sortable silt (SS) records for both sites also indicate slower bottom currents at this time, suggesting reduced deep water transport throughout the water column. $\delta^{13} \mathrm{C}$ and SS suggest reinvigorated deep water flow occurred in two steps during the deglaciation, consistent with the idea that shoaled NSW was unable to escape the Atlantic and contribute to deep flow in the Southern Indian Ocean, similar to observations from the Southern Pacific. From these data, we infer that Southern Ocean dynamics, rather than Atlantic overturning circulation, controlled the timing of early deglaciation in the Southern Hemisphere. 